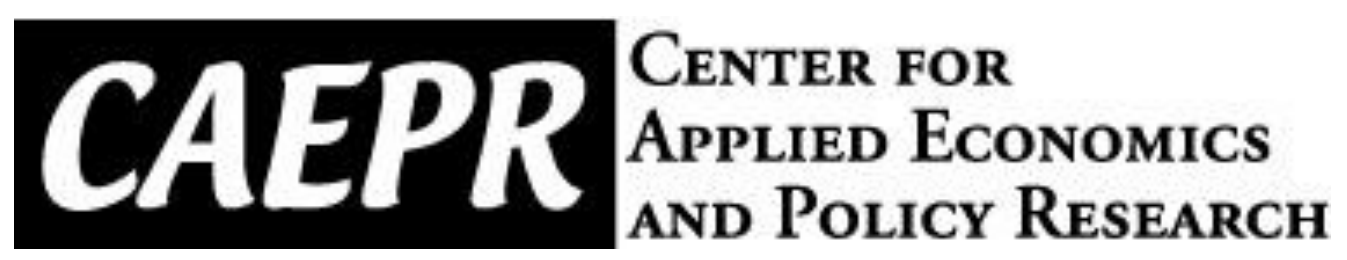

CAEPR Working Paper

\#2011-007

\title{
Cost-Effective Hiring in U.S. High Schools: Estimating Optimal Teacher Quantity and Quality Decisions
}

\author{
Anton Bekkerman and Gregory Gilpin \\ Montana State University
}

June 24, 2011

This paper can be downloaded without charge from the Social Science Research Network electronic library at: http://ssrn.com/abstract=1873508.

The Center for Applied Economics and Policy Research resides in the Department of Economics at Indiana University Bloomington. CAEPR can be found on the Internet at:

http://www.indiana.edu/ caepr. CAEPR can be reached via email at caepr@indiana.edu or via phone at 812-855-4050.

(C2011 by Anton Bekkerman and Gregory Gilpin. All rights reserved. Short sections of text, not to exceed two paragraphs, may be quoted without explicit permission provided that full credit, including $\odot$ notice, is given to the source. 


\title{
Cost-Effective Hiring in U.S. High Schools: Estimating Optimal Teacher Quantity and Quality Decisions
}

\author{
Gregory A. Gilpin and Anton Bekkerman
}

Extensive literature has shown that student attainment outcomes are affected by schools' decisions to alter student-to-teacher ratios and overall teacher aptitude levels. However, these findings provide little information to policymakers and school administrators for understanding which teacher input decision provides the greatest student attainment return relative to the associated costs. This study estimates cost-effective teacher input strategies for U.S. high schools seeking to either increase graduation rates or four-year college attendance rates by graduating students. Empirical results indicate that reducing student-to-teacher ratios is the most costeffective teacher input decision for high schools seeking to improve graduation rates. However, for schools whose objective is to increase four-year college attendance rates, it is more costeffective to allocate funds to improving teacher quality levels. These results put into question policies such as class size reduction mandates, which disregard schools' student attainment objectives and institute generalized teacher hiring constraints.

KEYWORDS: cost-effectiveness, teacher quality, class size, hiring strategies, student attainment

JEL classification codes: I22, J31, D24

Anton Bekkerman and Gregory Gilpin are Assistant Professors in the Department of Agricultural Economics and Economics at Montana State University. The corresponding author is Gregory Gilpin, gregory.gilpin@montana.edu, phone: (406) 994-5628. 


\section{Introduction}

Extensive research in the economics of education literature has debated whether raising students' attainment is best achieved by lowering student-to-teacher ratios or increasing teacher quality. ${ }^{1}$ This debate is misspecified. Undoubtedly, both strategies can improve student attainment levels; however, this fundamental knowledge provides little insight for policymakers and school administrators into choosing optimal teacher staffing strategies, especially when limited resources must be allocated to the most effective teacher input. Therefore, research focus must transform from investigating whether teacher staffing decisions are important to which strategy is most cost-effective. The purpose of this paper is to respecify and advance the teacher quantity/quality debate by quantifying the marginal student attainment returns for each dollar invested in reducing class sizes and raising teacher quality.

Currently, little research has compared the cost-effectiveness of changing student-to-teacher ratios and teacher quality levels, even though the cost-effectiveness valuation methods have been prevalent in the education literature. ${ }^{2}$ In fact, most studies do not jointly estimate marginal effects of changes in student-to-teachers ratios and teacher quality on student attainment. To

\footnotetext{
${ }^{1} \mathrm{~A}$ vast literature exists providing robust evidence that lowering student-to-teacher ratios or raising teacher quality are significant factors in increasing student attainment. For example, Angrist and Lavy (1999); Krueger (1999); McKee, Rivkin, and Sims (2010); Ding and Lehrer (2005) show positive effects on attainment from lower student-to-teacher ratios, and Summers and Wolfe (1977); Winkler (1975); Strauss and Sawyer (1986); Ferguson (1991, 1996); Ehrenberg and Brewer (1994) find similar positive correlation with teachers' aptitude scores. Moreover, Aaronson, Barrow, and Sander (2007); Monk (1994); Clotfelter, Ladd, and Vigdor (2007); Goldhaber and Anthony (2007) find that degree type and teaching credentials have statistically significant impacts on student achievement. In addition to evidence from the literature, a simple thought experiment demonstrates that changes in either the student-to-teacher ratio or teacher quality should affect attainment levels. Suppose that, ceteris parabus, a teacher is replaced with another higher-quality teacher. At the end of a sufficiently long experimental period, there is a trivial probability that student attainment is lower relative to the level expected to have been achieved with the lower-quality teacher. Rather, a higher-quality teacher will likely result in student attainment levels to be equal or greater. Similar outcomes are likely when, ceteris parabus, a teacher's class size is decreased.

${ }^{2}$ Levin's (1970) seminal study on cost-effectiveness in education illustrates a method for evaluating per dollar returns associated with implementing various strategies intended to increase student attainment. Other studies (as discussed in Levin (1988)) have used Levin's approach to investigate schools in specific districts.
} 
our knowledge, only Hanushek et al. (2005) and Clotfelter, Ladd, and Vigdor (2007) have sought to empirically investigate which teacher staffing strategy provides the largest impact on student attainment when both strategies are available. Both studies determine that for elementary school-aged children, increases in teacher quality offer greater student attainment returns than reductions in student-to-teacher ratios. However, these studies have a critical limitation: neither evaluates how empirical inferences and policy recommendations may change if financiallyconstrained schools are required to choose among the two teacher input strategies based on student attainment returns per invested dollar.

This study seeks to estimate cost-effective teacher staffing for increasing student attainment in high schools. The empirical analysis implements a heterogeneous set of U.S. high schools and the results indicate that optimal teacher input strategies are conditional on the effectiveness and costs associated with each strategy. Specifically, we examine and compare two teacher inputs identified by the literature to be consistently effective in improving student attainment: reductions in student-to-teacher ratios and increases in overall teacher quality. Exploiting variation in student-to-teacher ratios and teacher quality across U.S. high schools, we investigate how changes in these measures affect two student attainment outcomes: graduation rates and four-year college attendance rates by graduating seniors. ${ }^{3}$ To improve identification of these effects, our analysis explicitly controls for existing educational attainment measures and allows us to focus on high schools with specific attainment goals.

\footnotetext{
${ }^{3}$ There is some debate over appropriate measures of school outputs. At the high school level, either student test scores or educational attainment can measure achievement. Focusing on test scores permits an evaluation of a particular skill (e.g., reading comprehension), while educational attainment is an overall measure of a schools' performance to help students achieve a minimum set of skills. In this paper, we focus on educational attainment measures of student achievement. Focusing on educational attainment at the high school level is intuitive given the increased emphasis by policymakers and private organizations. For instances, the National Governors Association announced a thirteen-state $\$ 42$ million initiative in 2005 to lower high drop out rates and increase skills necessary for success in college or the workplace. Grad Nation, a national movement to raise the graduation rate of all schools to $90 \%$ by 2020, and the Winthrop Rockefeller Foundation's 'Move the Needle', are initiatives that targets graduation rates.
} 
The empirical estimation of cost-effective teacher input strategies is founded in a theoretical model of schools' hiring behaviors, which characterizes the interrelated employment decisions of schools and teachers, each of whom attempt to maximize their respective objective functions. We implement a two-stage estimation framework that controls for potential endogeneity between educational attainment measures and teacher characteristics. In the first stage, we model and jointly estimate schools' student-to-teacher ratios and teacher quality levels as a function of teacher, school, and community characteristics and exclusion restrictions (state-level mandates on bargaining on teacher compensation and class size limits, and state mandates on elementary school class sizes). Predicted first-stage teacher input estimates are then aggregated to the school level and used to estimate student attainment measures using quantile regressions. This modeling approach provides inferences about elasticities of teacher quantity and quality on student attainment across each student attainment distribution; however, these estimates offer no evidence as to which strategy is most cost-effective. To evaluate cost-effectiveness, we construct cost functions for each teacher input strategy, combine these with estimated student attainment returns elasticities, and determine optimal allocation of teacher input expenditures.

Our empirical results are consistent with findings in existing literature, which indicate that both student-to-teacher ratios and teacher quality have statistically significant effects on student attainment outcomes. Moreover, the estimated conditional quantiles show that changes in either teacher input affect four-year college attendance rates across the entire distribution of attendance rates, but changes in student-to-teacher ratios or teacher quality are ineffective in raising graduation rates in schools with high existing graduation rates. Furthermore, a $\$ 1,000$ investment in raising teacher quality, ceteris paribus, is on average $17 \%$ more cost-effective in increasing four-year college attendance rates than an equivalent investment in student-to-teacher ratio reduction. Conversely, $\$ 1,000$ invested to lowering student-to-teacher ratios is on average 
$19 \%$ more cost-effective in raising student graduation in schools with lower existing graduation rates. Lastly, we find that the cost-effectiveness of each teacher input decision is heterogeneous across schools with varying existing levels of four-year college attendance and graduation rates. This result can have important implications for improving efficient resource allocation to high schools, conditional on each school's existing student attainment levels. Doing so may be more optimal than imposing widespread, generalized teacher staffing requirements.

\section{A Theoretical Model of Educational Attainment}

Our theoretical model of schools' hiring behaviors follows the structure in Gilpin and Kaganovich (2011). We assume that the objective of high school administrators is to attain the highest per student education level, $E$, conditional on an exogenously administered budget, $B$. To achieve this objective, schools choose the total quantity, $Q=\int_{\Omega} h(n(\omega))$, and overall quality (teaching ability), $A=\int_{\Omega} g(\omega \cdot n(\omega))$, of its teachers, as well as the amount of other inputs not associated with teachers, $D .{ }^{4}$ When choosing a particular level of teacher quantity and quality, schools can hire an individual $n(\omega)$ with teaching ability $\omega \in \Omega$, where $\Omega$ represents an exogenously determined teaching ability distribution across all individuals. The school-level aggregation of these individuals and quality levels is characterized by the functions $h(\cdot)$ and $g(\cdot)$. Lastly, each teacher and non-teacher input level is associated with costs whose overall amount is assumed to exhaust a school's available resources.

A high school's maximization problem associated with a student attainment objective is

\footnotetext{
${ }^{4}$ School amenities available for students is one example of inputs that are not associated with teacher staffing decisions.
} 
characterized by the function:

$$
\begin{array}{ll} 
& \max _{\{n(\omega), D\}} E=f(Q, A, D) \\
\text { s.t. } & \\
& B=\int_{\Omega} w(\omega) n(\omega)+T
\end{array}
$$

where $w(\omega)$ represents the exogenously established market wage rate for an individual with teaching ability $\omega$, and $T$ are costs associated with non-teacher inputs. ${ }^{5}$ We assume that educational attainment, $E$, is increasing with diminishing marginal returns in each input. Lastly, in this study we focus on educational attainment outcomes associated with changes in teacher inputs, $Q$ and $A$, and therefore assume that schools use a separate teacher input budget, $\bar{B}<B$. In so doing, schools choose the quantity and quality of teachers that maximizes educational attainment for some constant level of non-teacher inputs, $D$.

In addition to budgetary constraints, schools' hiring decisions are indirectly affected by teachers' decisions to enter and/or remain in the teaching profession. Murnane and Olsen (1989), Eide, Goldhaber, and Brewer (2004), and Podgursky, Monroe, and Watson (2004) show that college graduates with high aptitude test scores are less likely to enter the teaching profession and employed teachers with high test scores are less likely to stay in the education section. Moreover, Ballou (1996) finds that wage offers in public schools are not high enough to attract individuals with better professional credentials. Therefore, in making optimal decisions about

\footnotetext{
${ }^{5}$ While the budget constraint specification may appear elementary, the school finance literature has shown that it is quite complex. First, the assumption that schools can obtain any quantity of a given quality teacher may not hold in all geographic areas or parts of the quality distribution. Jepsen and Rivkin (2009) show that there may exist a quantity-quality trade-off in the short-run when expanding quantity too rapidly. The literature on teacher mobility between schools has shown that the labor elasticity of supply for schools with a predominantly low socioeconomic student bodies is quite different than schools with predominantly high socioeconomic status student bodies (see Imazeki (2005) and Gilpin (2011a, 2011b). Second, non-teacher inputs may not be exogenous for some teacher hiring decisions such as large reductions in class sizes, which may require increased non-teaching inputs (see Hanushek (1979) for a further discussion).
} 
the student-to-teacher ratio and teacher quality level, schools must also consider whether a particular job offer will meet the wage, workload, and working environment expectations of a potential teacher with quality $\omega$. Secondly, state mandates associated with teacher bargaining rights and with working environments can also affect high schools' and teachers' employment decisions. These considerations are critical in evaluating cost-effectiveness associated with a particular educational attainment objective.

\section{Empirical Specification}

The theoretical framework outlines schools' strategies for maximizing student attainment by altering the student-to-teacher ratio, teacher quality, or both. These teacher recruitment and retention strategies are subject to a budget constraint and to considerations about whether a particular job offer, consisting of information about wages and non-pecuniary school characteristics, will attract a desired candidate. The observed aggregate teacher quantity and quality levels are the implicit cumulative outcomes of schools' recruiting and retention efforts, which aid in meeting a particular educational attainment objective; our empirical framework uses a two-stage estimation approach with exclusion restrictions to quantify these observed relationships.

\subsection{Returns to Student Attainment from Teacher Quantity and Quality}

The first stage of the empirical framework focuses on estimating educational attainment returns associated with implementing each of the two teacher input strategies. An important concern with directly estimating these relationships is that educational attainment measures and teacher input decisions are likely endogenous. Therefore, we provide appropriate identification of 
student-to-teacher ratio and teacher quality using a two-step estimation process. We first identify teacher input measures using exclusion restrictions and then use these estimates to model educational attainment measures.

Following our theoretical specification, we model teachers' wages as a function of teachers' experience, educational attainment, and bargaining constraints:

$$
w_{i, j}=\gamma_{0}+\gamma_{1} \boldsymbol{X}_{i}+\gamma_{2} \boldsymbol{X}_{j}+\gamma Z_{j}+v_{i, j}
$$

The term $w_{i, j}$ represents the annual salary of teacher $i$ in school $j, \boldsymbol{X}_{i}$ and $\boldsymbol{X}_{j}$ represent vectors of teacher and school characteristics, and $Z_{j}$ is a vector of constraints corresponding to teacher compensation and working conditions. Because our focus is to identify factors affecting teacher inputs rather than wages, we use a reduced-form specification for jointly modelling student-toteacher ratios and teacher quality. This reduced-form model is characterized by the following system of equations:

$$
\begin{aligned}
& q_{i, j}=\alpha_{0}+\alpha_{1} w_{i, j}+\alpha_{2} \boldsymbol{X}_{i}+\alpha_{3} \boldsymbol{X}_{j}+\alpha_{4} Z_{j}+\zeta_{i, j} \\
& a_{i, j}=\beta_{0}+\beta_{1} w_{i, j}+\beta_{2} \boldsymbol{X}_{i}+\beta_{3} \boldsymbol{X}_{j}+\beta_{4} \boldsymbol{Z}_{j}+\eta_{i, j}
\end{aligned}
$$

where $q_{i, j}$ is the average number of students in classes taught by teacher $i$ in school $j$ and $a_{i, j}$ is the observed scholastic aptitude of teacher $i .{ }^{6}$ We use the seemingly unrelated regression

\footnotetext{
${ }^{6}$ One could conceive of an alternative specification with wages, quantity and quality of teachers being simultaneously estimated. Indeed, Gilpin and Kaganovich (2011) demonstrate that only two of these three choice variables may be set and that the budget constraint determines the remaining variable. We choose to allow quantity and quality of teachers to be estimated and allow the budget constraint to determine wages, because our goal is to understand how wage constraints affect the quantity and quality of teachers. That is, we directly incorporates the wage function into equation (3) and estimate the reduced-form specification. A similar estimation strategy is performed by Stoddard (2003).
} 
estimator (SUR) with school-level cluster robust standard errors to jointly estimate equation (3). ${ }^{7}$

Next, we model educational attainment outcomes as functions of school aggregated predicted values, $\hat{Q}_{j}$ and $\hat{A}_{j}$. For each attainment type, estimation is performed using quantile regressions, which provide important inferences about heterogeneous marginal effects associated with changes in teacher inputs on educational attainment at schools in different parts of the conditional educational attainment distributions. In this manner, quantile regression estimations are used to understand differences in the effectiveness of each teacher input decision conditional on a school's existing attainment level. ${ }^{8}$ Conditional regression quantiles for educational attainment outcome $E$ are characterized by:

$$
E_{j}(\phi)=\delta_{0}(\phi)+\varepsilon_{E, Q}(\phi) \hat{Q}_{j}+\varepsilon_{E, A}(\phi) \hat{A}_{j}+\delta_{2}(\phi) \boldsymbol{Y}_{j}+v_{j}(\phi)
$$

where $0<\phi<1$ is the proportion of educational attainment $E_{j}$ in school $j$ with outcomes below the $\phi^{\text {th }}$ sample quantile, and $\boldsymbol{Y}_{j}$ represents a vector of school and community-level characteristics that may also affect educational attainment. Standard errors are appropriately estimated by bootstrapping.

For interpretative ease, coefficients associated with $Q_{j}$ and $A_{j}$ variables are presented as elasticities, which are directly estimated in a double-log model specification. That is, estimated coefficients $\varepsilon_{E, Q}$ and $\varepsilon_{E, A}$ are the elasticities of student attainment with respect to the studentto-teacher ratio and teacher quality. These estimates indicate the steepest change in student attainment due to changes in teacher inputs without accounting for costs of these changes.

\footnotetext{
${ }^{7}$ While unobservables could potentially bias the results, estimates using fixed effects models demonstrate that they are minimal and do not change the estimation results. This is likely due to the state-level exclusion restrictions capturing unobserved heterogeneity. These results are available upon request.

${ }^{8}$ For an overview of quantile regression methods, see Koenker (2005).
} 


\subsection{Estimating Cost-effective Hiring Strategies}

Given the above estimates that evaluate the effectiveness of reducing class size or raising teacher quality on student attainment, we construct corresponding cost estimates for each hiring strategy. As discussed in Levin (1988), cost-effectiveness analysis can be performed independently from an evaluation of costs or cost functions can be constructed during the evaluation of effectiveness by summing relevant costs. An advantage of jointly estimating cost functions and investigated policies is that costs include unanticipated expenditures or unknown costs associated with implementing these policies. A disadvantage is that these costs may not be very generalizable across school districts. Alternatively, estimating cost functions separately may be more generalizable but may not include all relevant costs. Thus, neither strategy is clearly optimal, and in an effort to minimize measurement error we use the same data sources for estimating policy effectiveness and expenditures associated with implementing teacher input decisions.

Because we estimate elasticities among teacher inputs and student attainment across the entire distribution of each attainment measure, we form corresponding cost estimates to particular parts of the student attainment distributions. It is necessary to note that rapidly reducing the student-to-teacher ratios may impose additional non-teaching costs, such as new facilities, or cause a quantity-quality trade-off due to a reduction of overall teacher quality through employment of less quality individuals. Therefore, we analyze policy interventions on the margin and do not attempt to estimate large changes in teacher quantities or qualities. Furthermore, we only analyze expenditures associated with schools hiring either the same quantity of teachers (but of higher quality) or more of the same quality of teachers (such that student-to-teacher ratios decrease without affecting overall teacher quality or non-school inputs). Thus, we only capture direct expenditures associated with policy changes rather 
than an aggregate measure of total teacher and non-teacher expenditures. For example, costs associated with reducing student-to-teacher ratios are per student expenditures necessary to lower a teacher's class size, and costs of increasing teacher quality are the wage expenditures required to hire higher quality teachers.

We estimate expenditure elasticities associated with reducing the student-to-teacher ratio and raising teacher quality at four quantiles in each of the student attainment distributions, $\phi=$ $\{20,40,60,80\}$. A general characterization of the expenditure elasticity between the $m^{\text {th }}$ teacher input ( $m=\{Q, A\})$ and associated cost, $w_{m}$, at the $\phi^{\text {th }}$ quantile of the $E^{\text {th }}$ educational attainment distribution is as follows:

$$
\varepsilon_{m, w_{m}}^{E}(\phi)=\frac{\Delta m(\phi)}{\Delta w_{m}(\phi)} \cdot \frac{\bar{w}_{m}(\phi)}{\bar{m}(\phi)} .
$$

We estimate the slope $\left(\Delta m(\phi) / \Delta w_{m}(\phi)\right)$ around a representative values within each quantile, $\bar{m}(\phi)$ and $\bar{w}_{m}(\phi)$, and evaluate the elasticity at those representative values. To assure that outliers do not bias the elasticity estimates, within each quantile of the student attainment distributions we determine the median for the teacher input and associated cost, use the median absolute deviation (MAD) to estimate the slope around those medians, and evaluate elasticities at the median value.

To form cost-effectiveness measures, we combine the estimated expenditure elasticities from equation (5) with estimated student attainment elasticities, $\varepsilon_{E, Q}(\phi)$ and $\varepsilon_{E, A}(\phi)$, shown in equation (4). After minor manipulations, a cost-effectiveness measure can be written as a percentage point change in educational attainment measure, $\Delta E$, resulting from a percentage change in costs, $\% \Delta w_{m}$, associated with increasing teacher input $m$. This cost-effectiveness measure is characterized as:

$$
\Delta E(\phi)=\varepsilon_{E, m}(\phi) \cdot \varepsilon_{m, w_{m}}^{E}(\phi) \cdot \% \Delta w_{m}(\phi) \cdot E(\phi)
$$


For two student attainment measures, two teacher inputs, and four quantiles, this procedures generates sixteen estimated cost-effectiveness elasticities.

\section{Data}

The primary data for this study come from the restricted-access versions of the 1999-2000, 200304, and the 2007-08 Schools and Staffing Survey (SASS) conducted by the National Center for Education Statistics. This survey incorporates questionnaires from roughly 50,000 teachers in 10,000 public schools every four years. The SASS data also contain precise teachers' wage and benefit characteristics and several workload measurements such as the number of students, classes, and preparations per teacher. Teachers' non-pecuniary environment descriptors include schools' racial and gender diversity and poverty measures, such as the percentage of students eligible for school lunch. The data also provide some limited school level student outcomes including the percent of $12^{\text {th }}$ graders who graduate and the percent of $12^{\text {th }}$ graders who attend four-year colleges. While these outcomes cannot be directly attributed to specific teachers, they are representative of whether or not schools have achieved their assumed student educational attainment goals.

Teacher quality is measured as a teacher's scholastic aptitude in percentiles. Among measurable teacher quality characteristics, the existing literature has shown that teachers' scholastic aptitudes have the strongest (and consistent) effect on student outcomes. ${ }^{9}$ We do, however, also control for other factors such as experience and education level. Since the SASS data do not contain a direct measure of teacher aptitude, data from six rounds (1989-90, 199293, 1995-96, 1999-00, 2003-04, 2007-08) of the restricted-access versions of the National PostSecondary Aid Survey (NPSAS) are used to construct scholastic achievement scores for each

\footnotetext{
${ }^{9}$ For example, see Greenwald, Hedges, and Laine (1996); Hanushek (1979, 1986); Hanushek et al. (2005).
} 
teacher. First, for each higher education institution we aggregate SAT and ACT scores of students attending the institution, creating a single score for each university. Then, we match each teacher in our sample to a representative aptitude score associated with the undergraduate institution attended by the teacher. As a scholastic ability measure, this may provide better precision than using either the selectivity of a higher education institution or its rank assigned by sources such as the U.S. News \& World Report or Barron's.

Information on bargaining mandates are provided by the National Council on Teacher Quality's TQ ${ }^{3}$ database. These data provide details about the permissibility and the requirements of various bargaining agreements, including the provisions for individuals to bargain on teachers' wages and class sizes in all fifty states and the District of Columbia. Collective bargaining by public school teachers is legally required, to some degree, in thirty-six of the fifty-one geographic entities. If teachers within a school are part of a collective bargaining agreement, then they collectively agree on a particular salary schedule. They may also bargain separately on a set of working conditions. In the remaining fifteen states, collective bargaining is voluntarily negotiated at the district level rather than being mandated by state law. We construct two variables from these data: whether schools are prohibited to collectively bargain for wages and for class size maximums. Furthermore, we use information on class size mandates in elementary schools from the Council for Education Policy, Research and Improvement to construct an indicator variable for whether the state also has an elementary school class size reduction mandate during the sample period. ${ }^{10}$

After constructing the necessary variables, we separate schools (and associated teachers) into two populations based on the school's existing student attainment outcomes: high graduation rates and low four-year college attendance rates. Identifying these populations has two important

\footnotetext{
${ }^{10}$ The Center also provides information on middle and high school class size mandates. However, almost no states have high school class size reduction mandates
} 
implications. First, we are able to classify schools' student attainment objectives based on their existing attainment levels and thus minimize the uncertainty of each school's true goals. The second implication is that creating separate school populations addresses the potential for teachers to self-select into schools based the school's existing student attainment levels. Gilpin (2011a) shows that an important factor explaining individuals' decisions to work in a particular school is schools' student attainment levels. Within each population, however, conditional sorting is minimized because at least one student attainment dimension is homogeneous and schools focus on improving a single objective. That is, student attainment measures do not contribute to explaining variation in the observed student-to-teacher ratio or teacher quality.

We assume that conditional on a school's existing level of either graduation or fouryear college attendance rates, the school may place greater focus on increasing a particular educational attainment measure. For example, schools that currently have very high graduation rates (have reached a capacity) may place greater weight on the objective to increase their students' four-year college attendance. Alternatively, schools with relatively low four-year college attendance rates may seek to maintain or improve graduation rates. That is, because four-year college attendance rates are bounded by graduation rates (students are unable to attend a college without first graduating high school), the population of high schools that fall in the lower part of the college attendance distribution can be used to investigate how teacher staffing decisions affect graduation rates. Figure 1 shows that there is a wide distribution of four-year college attendance rates for high schools that graduate nearly all of their students and substantial graduation rate variation among schools for which we observe low four-year college attendance rates. Conditioning the empirical analyses on schools' existing level of educational attainment allows for a natural separation of data, which can offer more straightforward inferences about cost-effective educational attainment improvement strategies for each attainment objective. We 
assume that schools in each population focus on one objective, and they do so by altering the student-to-teacher ratio and/or the teacher quality level. ${ }^{11}$

To construct the appropriate populations, we determine thresholds that separate schools into those with high graduation rates and those with low four-year college attendance rates. Thresholds are estimated using a grid-search in order to determine the highest possible value for four-year college attendance rates and the lowest possible graduation rate such that within the resulting school populations, $t$ - and $F$-tests indicate that student attainment measures do not significantly determine either teacher quality or student-to-teacher ratios in equation (3). The estimated threshold is $99 \%$ for schools with very high graduation rates focused on raising college attendance and $45 \%$ for schools with low college attendance rates focused on raising graduation rates. Tables 1 and 2 summarize the variables used in the estimations and provides summary statistics for the two types of school populations.

\section{Results of Empirical Analyses}

\subsection{Estimation Results of the Teacher Quantity and Quality Models}

Our empirical strategy is intended to provide appropriate identification for the numerous complexities associated with characterizing the relationship among teacher quantity and quality, student attainment measures, and state mandates. For each school population type, we estimate factors affecting teacher input decisions in high schools using seemingly unrelated regressions (SUR). Exclusion restrictions used for appropriate identification of teacher inputs are consistent with those implemented by studies in the existing literature (for example, see Hoxby, 1996; ?; ?;

\footnotetext{
${ }^{11}$ As discussed in footnote 5 , teachers may self-select into schools with desired student attainment levels. Sub-sampling data by existing attainment levels eliminates this selection problem and provides a medium for investigating unidirectional impacts of teachers on student attainment.
} 
?). We include four exclusion restrictions: the first restriction is whether the school (or teacher) is in a state that permits collective bargaining for compensation; the second is whether the school (or teacher) is in a state that permits collective bargaining for working environments; the third is whether the state has an elementary school class size mandate; and the fourth is the percent of school finance appropriated by local funding.

Table 3 (top) presents SUR estimation results for schools that seek to improve four-year college attendance rates. As expected, high schools located in more affluent communities tend to have lower student-to-teacher ratios, as indicated by the statistically significant effects of higher median community incomes and the interaction between median community income and percent of school finance appropriated by local funding. Moreover, schools with a higher proportion of students eligible for free lunches have lower student-to-teacher ratios. Furthermore, student-toteacher ratios can be identified by evaluating state school-related policies. States that mandate lower elementary schools' class sizes, potentially diverting resources away from high schools, tend to have higher student-to-teacher ratios in high schools. ${ }^{12}$ Lastly, teachers in rural schools tend to have lower student-to-teacher ratios.

Teacher quality is identified by teacher, school, and community characteristics and state mandates. Increases in the number of teachers with Master's degrees raise the overall quality of the teacher body. However, the estimated negative marginal effect of the interaction between teacher quality and more experienced individuals indicates that individuals of lower aptitude who remain in education tend to compensate with additional education. Furthermore, schools located in states where teachers are able to bargain either on compensation or their work environment raises teacher quality. Lastly, schools located in communities with higher median community

\footnotetext{
${ }^{12}$ Bargaining collectively for wages or work environment are statistically insignificant. Although this is somewhat surprising, it is necessary to note that when elementary schools class size mandates are excluded from the regression, the coefficient associated with the mandate to bargain for work environment conditions becomes significant. Therefore, it seems that both variables' effects cannot be identified jointly.
} 
incomes, where a higher percentage of income is funded locally and there is a lower proportion of minority students, have higher teacher quality. ${ }^{13}$

Table 3 (bottom) presents SUR estimation results for schools seeking to improve graduation rates. Except for slight variation in the marginal effect magnitudes, variables that statistically significantly identify student-to-teacher ratios and overall teacher quality in schools focusing on improving college attendance rates are also ones that identify teacher quantity and quality measures in schools seeking to raise graduation rates. Although this is of little surprise, there is one difference. Teacher quality is not identified by state mandates providing teachers with the ability to collectively bargain on working environments. This is likely because policies targeting lower student-to-teacher ratios already exist in this school population, which substantially reduces teachers' abilities to bargain on class size.

\subsection{Estimation Results of the Student Achievement Model}

Using the above results, we construct aggregate predicted student-to-teacher ratios and teacher quality for the second-stage estimation. These predicted measures are exogenous to student attainment and are used to explain variation in attainment measures. To evaluate these relationships, we estimate quantile regressions for each student attainment distribution and perform a 250-iteration bootstrap to approximate standard errors. Specifically, in each school population, we estimate separate quantile regressions for estimating teacher inputs affecting four-year college attendance rates and graduation rates. Estimated conditional quantiles provide important inference about potential non-linear marginal effects of teacher inputs on attainment measures across the student attainment distributions. Both student attainment measures and all continuous explanatory variables are in natural log form.

\footnotetext{
${ }^{13}$ While teachers can sort on student body characteristics, as discussed in the previous section, we verify that teachers do not sort on student attainment.
} 
For schools focusing on raising four-year college attendance rates, quantile regression results for the $20^{\text {th }}, 40^{\text {th }}, 60^{\text {th }}$, and $80^{\text {th }}$ sample quantiles are presented in Table 4 and for the entire fouryear college attendance rate distribution in Figure 2. Both descriptive and visual estimation results indicate that reducing student-to-teacher ratio or increasing teacher quality levels have statistically significant marginal effects on raising four-year college attendance rates across the entire conditional college attendance rate distribution. However, these marginal effects are non-linear, because changes in student-to-teacher ratios or teacher quality have greater impacts on improving college attendance in schools with low existing college attendance rates than in schools with high existing college attendance rates. At the $20^{\text {th }}$ sample quantile, a $1 \%$ increase in teacher quality raises college attendance by $1.82 \%$, and at the $80^{\text {th }}$ sample quantile, the marginal effects falls to $0.74 \%$. Similarly, a $1 \%$ decrease in the student-to-teacher ratio increases four-year college attendance rates by $1.33 \%$ at the $20^{\text {th }}$ sample quantile and by $0.97 \%$ at the $80^{\text {th }}$ quantiles. Therefore, because both teacher inputs have statistically significant effects on raising four-year college attendance rates, cost-effectiveness measures are necessary to determine which teacher input change will maximize student attainment returns per unit of investment. ${ }^{14}$

Quantile regression results for schools whose objective is to improve graduation rates are also presented in Table 4 and Figure 3. General inferences from these results are similar to those estimated for the school population seeking to raise four-year college attendance rates. Marginal effects of both student-to-teacher ratio and overall teacher quality are statistically significant across the majority of the conditional graduation rate distribution and become statistically insignificant at the upper-most $\left(80^{\text {th }}\right)$ sample quantile. Both teacher inputs have the largest marginal impacts on graduation rates in high schools where existing graduation rates are low, but the magnitude of these impacts decrease for schools with higher existing graduation rates.

\footnotetext{
${ }^{14}$ It should be noted that even if the one hiring strategy dominates the other in terms of magnitude of effect on the student attainment, the costs may be prohibitively high to implement.
} 
Specifically, a $1 \%$ decrease in the student-to-teacher ratio or a $1 \%$ increase in teacher aptitude will increase graduation by $0.48 \%$ and $0.76 \%$, respectively, in the lowest $20^{\text {th }}$ sample quantile. At the $60^{\text {th }}$ sample quantile, these effects are only $0.12 \%$ and $0.25 \%$, respectively. It is interesting to note that the return to teacher inputs is larger on raising college attendance rates than raising graduation rates.

\subsection{Results of the Cost-Effectiveness Analysis}

Results of the quantile regressions indicate that improvements in student attainment can be achieved through changes in either student-to-teacher ratios or teacher quality levels. However, these results provide little information about the degree to which student attainment can improve for a given change in teacher input expenditures. This study intends to go beyond simply showing that altering either of these two factors is important, providing an understanding of the cost-effectiveness of each strategy. The quantile regression results provide a fundamental understanding of student attainment elasticities with respect to changes in teacher inputs; constructing expenditures elasticities will aid in understanding how costly it is to change teacher quantity and quality.

Estimated cost-effectiveness measures for altering both student attainment measures are presented in Table 5. ${ }^{15}$ For schools seeking to increase four-year college attendance rates and with existing attendance rates in the $20^{\text {th }}, 40^{\text {th }}$, or $60^{\text {th }}$ sample quantiles, it is most cost-effective to increase expenditures on improving teacher quality, and in the $80^{\text {th }}$ sample quantile, reducing student-to-teacher ratio becomes more cost-effective. Specifically, for a $\$ 1,000$ per teacher base salary increase for higher quality teachers (maintaining the existing student-to-teacher ratio), college attendance rates increase by $0.77,1.32$ and 1.12 percentage points for high schools in

\footnotetext{
${ }^{15}$ Intermediate information necessary to estimate final cost-effectiveness measures are presented in Table 4.
} 
the $20^{\text {th }}, 40^{\text {th }}$, or $60^{\text {th }}$ sample four-year college attendance quantiles. The same expenditure on reducing student-to-teacher ratios (maintaining the existing level of teacher quality) would result in $0.54,1.03$ and 0.86 percentage point college attendance increases. However, for schools in the $80^{\text {th }}$ sample quantile, a $\$ 1,000$ per teacher base salary increase should be allocated to decreasing student-to-teacher ratios, because doing so increases college attendance rates by 0.35 percentage points more than increasing teacher quality. The switch in cost-effective teacher input strategies at the highest sample quantile is due to a much rapid decrease in the returns to teacher quality across the four-year college attendance distribution. This implies that for schools with high existing college attendance rates, it is more cost-effective to hire an additional teacher, who will have a similar quality as the existing teacher body, than to attempt to marginally increase overall teacher aptitude at an excessive cost.

Results presented Table 5 also indicate that for high schools seeking to increase graduation rates, it is always more cost-effective to reduce student-to-teacher ratios. For a $\$ 1,000$ per teacher base salary increase, high schools in the $20^{\text {th }}, 40^{\text {th }}$, or $60^{\text {th }}$ sample graduation rate quantiles can experience $0.06,0.03$, and 0.20 percentage points additional graduation when reducing student-to-teacher ratios than when allocating the funds to improving teacher quality. Because the estimated marginal effects of teacher inputs on student attainment measures are statistically insignificant at the $80^{\text {th }}$ sample quantile, we are unable to infer cost-effectiveness measures for schools with relatively high existing graduation rates.

\section{Conclusions and Policy Implications}

Improving student attainment outcomes is a major objective of school administrators and policymakers. Consequently, the literature has focused on investigating factors affecting attainment levels. Studies have repeatedly found that attainment outcomes are significantly 
impacted by teacher input decisions. However, although critical to understanding approaches for improving student attainment, these studies cannot be used to infer which teacher input decision is optimal. First, while most research does account for student body characteristics, few explicitly condition teacher input strategies on schools' existing attainment levels, generalizing policy recommendations across schools that may have different student attainment objectives. More importantly, policy recommendations do not account for costs associated with implementing a reduction in student-to-teacher ratios or an increase in teacher quality. Therefore, the impact of altering a particular teacher input is much less certain when schools face budgetary constraints.

This study advances the literature by estimating cost-effective teacher input strategies for U.S. high schools seeking to increase graduation rates or four-year college attendance rates. Our empirical results indicate that there is no comprehensive teacher input policy for increasing student attainment levels, and that the impacts of particular teacher input decisions are not homogeneous across high schools. Specifically, for high schools seeking to increase graduation rates, it is more cost-effective to reduce student-to-teacher ratios rather than raise teacher quality. That is, there is a greater student attainment return from a dollar of investment in reducing class sizes than from investing in teacher quality. Conversely, increasing teacher quality is a more cost-effective strategy for schools whose objective is improving four-year college attendance rates for schools below the $80^{\text {th }}$ percentile in the college attendance distribution while the investing in lowering the student-to-teacher ratio is more cost-effective at above the $80^{\text {th }}$ percentile. However, for both student attainment objectives, the marginal effect of investments in a particular teacher input decreases as schools' attainment levels increase.

Our findings bring into question the use of unconditional, blanket state mandates and hiring constraints imposed by policymakers. The results of our analysis make clear that these 
constraints can bind the quantity and quality of hired teachers. Consequently, these constraints can lead to substantial inefficiencies in the teacher input decision-making process and contribute to foregone student attainment improvements if they are binding. For example, imposing a class size mandate on high schools seeking to improve four-year college attendance rates can cause these schools to sub-optimally allocate investments into teacher inputs that do not maximize attainment returns. Therefore, because high schools in the same state (or even district) may not have the same student attainment levels and objectives, effective policies must account for potential heterogeneity that exists across these schools.

Because both the quantity and quality of teachers are effective at improving student attainment levels, the results of this study provide a first step to respecifying the teacher quantity/quality debate from estimating effective hiring strategies to estimating cost-effective hiring strategies. This requires researchers to not only evaluate school and teacher policy effects on student attainment, but to determine how costs associated with implementing each policy can impact the policy's effectiveness. 


\section{References}

Aaronson, D., L. Barrow, and W. Sander. 2007. "Teachers and Student Achievement in the Chicago Public High Schools.” Journal of Labor Economics 25:95-135.

Angrist, J., and V. Lavy. 1999. “Using Maimonides’ Rule To Estimate The Effect Of Class Size On Scholastic Achievement." Quarterly Journal of Economics 114:533-575.

Ballou, D. 1996. "Do Public Schools Hire the Best Applicants?" Quarterly Journal of Economics 111:97-133.

Clotfelter, C., H. Ladd, and J. Vigdor. 2007. "How and Why do Teacher Credentials Matter for Student Achievement?" NBER Working Papers No. 12828, National Bureau of Economic Research, Inc, Jan.

Ding, W., and S. Lehrer. 2005. "Class Size and Student Achievement: Experimental Estimates of Who Benefits and Who Loses from Reductions.” Working Papers No. 1046, Queen's University, Department of Economics, Sep.

Ehrenberg, R., and D. Brewer. 1994. "Do school and teacher characteristics matter? Evidence from High School and Beyond." Economics of Education Review 13:1-17.

Eide, E., D. Goldhaber, and D. Brewer. 2004. “The Teacher Labour Market and Teacher Quality.” Oxford Review of Economic Policy 20:230-244.

Ferguson, R. 1996. "How and Why Money Matters: An Analysis of Alabama Schools." In H. Ladd, ed. Holding Schools Accountable: performance-based reform in education. Brookings Institution Press, chap. 8, pp. 465-98. 
—. 1991. "Paying For Public Education: New Evidence on How and Why Money Matters." Journal on Legislation, pp. 465-498.

Gilpin, G. 2011a. "Reevaulating the Effect of Non-teaching Wages on Teacher Attrition." Economics of Education Review 30:598-616.

—. 2011b. "Salary Schedules, Teacher Sorting, and Teacher Quality." Working paper No. 004, CAEPR Working Paper Series.

Gilpin, G., and M. Kaganovich. 2011. "The Quantity and Quality of Teachers: A Dynamic Trade-off.” CAEPR Working Paper No. 2011-006, Indiana University.

Goldhaber, D., and E. Anthony. 2007. "Can Teacher Quality Be Effectively Assessed? National Board Certification as a Signal of Effective Teaching." Review of Economics and Statistics 89:134-150.

Greenwald, R., L. Hedges, and R. Laine. 1996. "The Effect of School Resources on Student Achievement." Review of Educational Research 66:361-396.

Hanushek, E. 1979. "Conceptual and Empirical Issues in the Estimation of Educational Production Functions.” Journal of Human Resources 14:351-388.

—. 1986. "The Economics of Schooling: Production and Efficiency in Public Schools." Journal of Economic Literature 24:1141-77.

Hanushek, E., J. Kain, D. O'Brien, and S. Rivkin. 2005. "The Market for Teacher Quality." Working Paper No. 11154, National Bureau of Economic Research, February.

Hoxby, C. 1996. "How Teachers' Unions Affect Education Production." Quarterly Journal of Economics 111:671-718. 
Imazeki, J. 2005. "Teacher salaries and teacher attrition." Economics of Education Review $24: 431-449$.

Jepsen, C., and S. Rivkin. 2009. "Class Size Reduction and Student Achievement: The Potential Tradeoff between Teacher Quality and Class Size." Journal of Human Resources 44.

Koenker, R., ed. 2005. Quantile Regression. Cambridge University Press, New York, NY.

Krueger, A. 1999. "Experimental Estimates of Education Production Functions*." Quarterly Journal of Economics 114:497-532.

Levin, H. 1970. “A Cost-Effectiveness Analysis of Teacher Selection.” Journal of Human Resources 5:24-33.

-. 1988. "Cost-Effectiveness and Educational Policy." Educational Evaluation and Policy Analysis 10:51-69.

McKee, G., S. Rivkin, and K. Sims. 2010. "Disruption, Achievement and the Heterogeneous Benefits of Smaller Classes.” Working Paper No. 15812, National Bureau of Economic Research, March.

Monk, D. 1994. "Subject area preparation of secondary mathematics and science teachers and student achievement." Economics of Education Review 13:125-145.

Murnane, R., and R. Olsen. 1989. "The Effect of Salaries and Opportunity Costs on Duration in Teaching: Evidence from Michigan.” Review of Economics and Statistics 71:347-352.

Podgursky, M., R. Monroe, and D. Watson. 2004. "The academic quality of public school teachers: an analysis of entry and exit behavior." Economics of Education Review 23:507518. 
Stoddard, C. 2003. "Why has the number of teachers per student risen while teacher quality has declined?: The role of changes in the labor market for women." Journal of Urban Economics $53: 458-481$.

Strauss, R., and E. Sawyer. 1986. "Some new evidence on teacher and student competencies." Economics of Education Review 5:41-48.

Summers, A., and B. Wolfe. 1977. “Do Schools Make a Difference?” American Economic Review 67:639-52.

Winkler, D. 1975. "Educational Achievement and School Peer Group Composition.” Journal of Human Resources 10:pp. 189-204. 
Table 1: Variable Descriptions and Summary Statistics for Hiring Decision Regressions

\begin{tabular}{|c|c|c|c|c|}
\hline \multirow[t]{2}{*}{ Variable $^{a}$} & \multicolumn{2}{|c|}{ College Attendance $e^{b}$} & \multicolumn{2}{|c|}{ Graduation $^{c}$} \\
\hline & Mean & Std. Dev. & Mean & Std. Dev. \\
\hline \multicolumn{5}{|l|}{ Dependent Variables } \\
\hline Student-to-teacher ratio & 20.52 & 8.83 & 22.71 & 9.50 \\
\hline Teacher quality - aptitude & 50.96 & 16.44 & 49.23 & 16.40 \\
\hline \multicolumn{5}{|l|}{ Teacher Characteristics } \\
\hline Years of teaching experience & 14.31 & 10.62 & 13.55 & 10.37 \\
\hline Has Master's degree & 0.47 & & 0.46 & \\
\hline \multicolumn{5}{|l|}{ School Characteristics } \\
\hline Percent of students eligible for free lunch & 15.85 & 23.17 & 21.08 & 27.57 \\
\hline Percent minority students & 20.20 & 25.67 & 34.78 & 31.86 \\
\hline In metro area & 0.12 & & 0.21 & \\
\hline In rural area & 0.48 & & 0.38 & \\
\hline \multicolumn{5}{|l|}{ Community Characteristics } \\
\hline Median income ${ }^{d}$ & $\$ 49.5$ & $\$ 19.2$ & $\$ 45.7$ & $\$ 14.3$ \\
\hline \multicolumn{5}{|l|}{ Hiring Decision Constraints } \\
\hline Collective bargaining for compensation mandate in state & 0.66 & & 0.59 & \\
\hline Collective bargaining for working conditions mandate in state & 0.19 & & 0.16 & \\
\hline Elementary school class size mandate in state & 0.45 & & 0.51 & \\
\hline Percent of school finance appropriated by local finance & 0.45 & 0.21 & 0.39 & 0.18 \\
\hline Sample Size ${ }^{e}$ & \multicolumn{2}{|c|}{4,290} & \multicolumn{2}{|c|}{8,670} \\
\hline
\end{tabular}

${ }^{a}$ Standard deviations are not reported for $0 / 1$ dummy variables.

${ }^{b}$ Observations are from population of schools in which graduation rates are greater than or equal to $99 \%$.

${ }^{c}$ Observations are from population of schools in which four-year college attendance rates are less than or equal to $45 \%$.

${ }^{d}$ In thousands of 2007 dollars.

${ }^{e}$ All sample sizes are rounded to nearest 10 to comply with data-use license restriction. 
Table 2: Variable Descriptions and Summary Statistics for Student Attainment Regressions

\begin{tabular}{|c|c|c|c|c|}
\hline \multirow[t]{2}{*}{ Variable $^{a}$} & \multicolumn{2}{|c|}{ College Attendance ${ }^{b}$} & \multicolumn{2}{|c|}{ Graduation $^{c}$} \\
\hline & Mean & Std. Dev. & Mean & Std. Dev. \\
\hline Dependent Variable & 50.987 & 21.630 & 90.051 & 14.549 \\
\hline \multicolumn{5}{|l|}{ Hiring Decision Characteristics } \\
\hline Student-to-teacher ratio & 18.80 & 6.54 & 21.34 & 6.15 \\
\hline Teacher quality & 49.80 & 11.09 & 49.46 & 10.71 \\
\hline \multicolumn{5}{|l|}{ School Characteristics } \\
\hline Percent of students eligible for free lunch & 19.74 & 25.46 & 16.41 & 22.62 \\
\hline Total students in school & 457 & 451 & 688 & 558 \\
\hline In metro area & 0.04 & & 0.16 & \\
\hline In rural area & 0.45 & 0.44 & 0.59 & 0.47 \\
\hline \multicolumn{5}{|l|}{ Community Characteristics } \\
\hline Percent with Bachelor's degree or higher & 0.25 & .16 & 0.24 & .13 \\
\hline Sample Size ${ }^{e}$ & \multicolumn{2}{|c|}{570} & \multicolumn{2}{|c|}{1,330} \\
\hline
\end{tabular}

${ }^{a}$ Standard deviations are not reported for $0 / 1$ dummy variables.

${ }^{b}$ Observations are from population of schools in which graduation rates are greater than or equal to $99 \%$.

${ }^{c}$ Observations are from population of schools in which four-year college attendance rates are less than or equal to $45 \%$.

${ }^{d}$ In 2007 dollars.

${ }^{e}$ All sample sizes are rounded to nearest 10 to comply with data-use license restriction. 
Table 3: SUR Estimation Results for Student-to-teacher ratio and Teacher Quality

\begin{tabular}{lcccc}
\multicolumn{4}{c}{ Four-year College Attendance Rate } \\
& \multicolumn{2}{c}{ Student-to-teacher ratio } & \multicolumn{2}{c}{ Teacher quality } \\
& Coef. & t-value & Coef. & t-value \\
\hline Total experience & 0.120 & 0.94 & -0.276 & -1.22 \\
Total experience, squared & -0.001 & -0.23 & 0.009 & 1.47 \\
Masters degree & 1.511 & 1.05 & $10.832^{* * * *}$ & 4.28 \\
Tot. exp $\times$ masters degree & -0.023 & -0.28 & $-0.350^{* *}$ & -2.44 \\
Percent students eligible for free lunch & $-0.049^{* * *}$ & -4.23 & -0.023 & -1.12 \\
Percent minority students & 0.009 & 0.69 & $-0.083^{* * *}$ & -3.84 \\
Metro school & 1.174 & 0.85 & 0.861 & 0.35 \\
Rural school & $-3.722^{* * *}$ & -5.67 & $-1.978^{*}$ & -1.70 \\
Median income & $0.202^{* * *}$ & 3.62 & $0.362^{* * *}$ & 3.48 \\
Median income $\times \%$ local funds & $-0.238^{* * *}$ & -3.10 & $-0.494^{* * *}$ & -3.42 \\
Bargaining for class size & 0.784 & 1.01 & $2.883^{* *}$ & 2.10 \\
Bargaining for wages & - & - & $2.266^{* *}$ & 2.22 \\
Elem. school class size mandate & $1.558^{* * *}$ & 2.89 & - & - \\
$\%$ local funds & 5.254 & 1.36 & $23.115^{* * *}$ & 3.27 \\
Constant & $12.458^{* * *}$ & 4.62 & $33.285^{* * *}$ & 7.05 \\
$R^{2}$ & \multicolumn{4}{c}{0.208} \\
\hline
\end{tabular}

Graduation Rate

\begin{tabular}{lcccc}
\hline & \multicolumn{2}{c}{ Student-to-teacher ratio } & \multicolumn{2}{c}{ Teacher quality } \\
& Coef. & t-value & Coef. & t-value \\
\hline Total experience & 0.031 & 0.29 & 0.069 & 0.38 \\
Total experience, squared & -0.002 & -0.54 & -0.001 & -0.17 \\
Masters degree & 0.443 & 0.43 & $6.793 * * *$ & 3.76 \\
Tot. exp $\times$ masters degree & 0.062 & 1.05 & $-0.259^{* *}$ & -2.49 \\
Percent students eligible for free lunch & $-0.026 * * *$ & -3.99 & -0.012 & -1.02 \\
Percent minority students & 0.003 & 0.38 & $-0.062^{* * *}$ & -5.43 \\
Median income & $0.083^{* * *}$ & 2.67 & $0.335^{* * *}$ & 6.05 \\
Median income $\times$ \% local funds & $-0.137 * * *$ & -2.76 & $-0.459 * * *$ & -5.26 \\
Metro school & 0.794 & 1.36 & $2.438^{* *}$ & 2.39 \\
Rural school & $-3.730^{* * *}$ & -8.66 & -0.295 & -0.39 \\
Bargaining for class size & 0.354 & 0.76 & 0.349 & 0.42 \\
Bargaining for wages & - & - & $2.129 * * *$ & 3.45 \\
Elem. school class size mandate & $0.615^{*}$ & 1.83 & - & - \\
$\%$ local funds & 2.686 & 1.05 & $27.539 * * *$ & 6.07 \\
Constant & $20.179 * * *$ & 12.38 & $30.811^{* * *}$ & 10.88 \\
$R^{2}$ & \multicolumn{4}{c}{0.128} \\
\hline
\end{tabular}

$*, * *$, and $* * *$ indicate statistical significance at the $10 \%, 5 \%$, and $1 \%$ levels. 
Table 4: Estimated Educational Attainment Effectiveness of Quantity and Quality of Teachers and Teacher Input Cost Elasticities

Four-year College Attendance Rates

\begin{tabular}{lllll}
\hline & $20^{\text {th }}$ quantile & $40^{\text {th }}$ quantile & $60^{\text {th }}$ quantile & $80^{\text {th }}$ quantile \\
\hline$\varepsilon_{C, Q}$ & $-1.325^{*}$ & $-1.317^{* * *}$ & $-1.018^{* * *}$ & $-0.972^{* * *}$ \\
$\varepsilon_{C, A}$ & $1.820^{* *}$ & $1.442^{* * *}$ & $1.150^{* * *}$ & $0.735^{* * *}$ \\
$\varepsilon_{Q, w_{Q}}^{C}$ & -0.940 & -0.989 & -0.858 & -0.878 \\
$\varepsilon_{A, w_{A}}^{C}$ & 0.951 & 1.140 & 0.946 & 0.771 \\
$\varepsilon_{C, w_{Q}}$ & 1.246 & 1.303 & 0.874 & 0.853 \\
$\varepsilon_{C, w_{A}}$ & 1.730 & 1.643 & 1.088 & 0.566 \\
Median student-to-teacher ratio & 20.665 & 21.830 & 22.123 & 21.603 \\
Median aptitude points & 47.601 & 49.780 & 50.484 & 50.802 \\
Median cost per student & $\$ 2,112$ & $\$ 2,033$ & $\$ 2,067$ & $\$ 2,067$ \\
Median cost per aptitude point & $\$ 911$ & $\$ 886$ & $\$ 890$ & $\$ 888$ \\
Four-year college attendance rate & 19 & 35 & 45 & 55 \\
\hline
\end{tabular}

Graduation Rates

\begin{tabular}{lllll}
\hline & $20^{\text {th }}$ quantile & $40^{\text {th }}$ quantile & $60^{\text {th }}$ quantile & $80^{\text {th }}$ quantile \\
\hline$\varepsilon_{G, Q}$ & $-0.756^{* * *}$ & $-0.370^{* * *}$ & $-0.245^{* * *}$ & -0.057 \\
$\varepsilon_{G, A}$ & $0.483^{* * *}$ & $0.242^{* * *}$ & $0.123^{* * *}$ & 0.013 \\
$\varepsilon_{Q, w_{Q}}^{G}$ & -0.878 & -0.787 & -0.854 & -0.738 \\
$\varepsilon_{A, w_{A}}^{G}$ & 1.281 & 1.104 & 0.917 & 1.019 \\
$\varepsilon_{G, w_{Q}}$ & 0.663 & 0.291 & 0.209 & 0.042 \\
$\varepsilon_{G, w_{A}}$ & 0.619 & 0.267 & 0.113 & 0.013 \\
Median student-to-teacher ratio & 22.324 & 22.462 & 22.022 & 21.500 \\
Median aptitude points & 49.427 & 50.637 & 50.730 & 51.423 \\
Median cost per student & $\$ 2,058$ & $\$ 2,036$ & $\$ 2,051$ & $\$ 2,071$ \\
Median cost per aptitude point & $\$ 909$ & 894 & 906 & 869 \\
Graduation Rate & 84.0 & 92.2 & 95.5 & 97.5 \\
\hline
\end{tabular}

$*, * *$, and $* * *$ indicate statistical significance at the $10 \%, 5 \%$, and $1 \%$ levels in quantile regression estimations.

$\varepsilon_{C, Q}\left(\varepsilon_{G, Q}\right)$ : Elasticity of college attendance (graduation) rate w.r.t. changes in student-to-teacher ratio. Quantile regression estimates of equation (4). Full results available upon request.

$\varepsilon_{C, A}\left(\varepsilon_{G, A}\right)$ : Elasticity of college attendance (graduation) rate w.r.t. changes in teacher quality. Quantile regression estimates of equation (4). Full results available upon request.

$\varepsilon_{Q, w_{Q}}^{C}\left(\varepsilon_{Q, w_{Q}}^{G}\right)$ : Elasticity of student-to-teacher ratio w.r.t. costs per student for college attendance (graduation).

$\varepsilon_{A, w_{A}}^{C}\left(\varepsilon_{A, w_{A}}^{G}\right)$ : Elasticity of teacher quality w.r.t. costs per aptitude point for college attendance (graduation).

$\varepsilon_{C, w_{Q}}\left(\varepsilon_{G, w_{Q}}\right)$ : Elasticity of college attendance (graduation) rate w.r.t. costs per student.

$\varepsilon_{C, w_{A}}\left(\varepsilon_{G, w_{A}}\right)$ : Elasticity of college attendance (graduation) rate w.r.t. costs per aptitude point. 
Table 5: Cost-effectiveness per $\$ 1,000$ teacher input investment ${ }^{a}$

Four-year College Attendance Rates

\begin{tabular}{lllll}
\hline & $20^{\text {th }}$ quantile & $40^{\text {th }}$ quantile & $60^{\text {th }}$ quantile & $80^{\text {th }}$ quantile \\
\hline Lower student-to-teacher ratio & 0.543 & 1.027 & 0.860 & 1.051 \\
Raise teacher quality & 0.766 & 1.322 & 1.120 & 0.702 \\
\hline
\end{tabular}

Graduation Rates

\begin{tabular}{lllll}
\hline & $20^{\text {th }}$ quantile & $40^{\text {th }}$ quantile & $60^{\text {th }}$ quantile & $80^{\text {th }}$ quantile $^{b}$ \\
\hline Lower student-to-teacher ratio & 1.213 & 0.586 & 0.442 & 0.092 \\
Raise teacher quality & 1.150 & 0.552 & 0.241 & 0.030 \\
\hline
\end{tabular}

${ }^{a}$ Percentage point change in educational attainment associated with a $\$ 1,000$ base pay per teacher change in teacher input investments.

${ }^{b}$ Changes in student-to-teacher ratios or teacher quality have no statistically significant effect on increasing graduation rates in the $80^{\text {th }}$ sample quantile. 
Figure 1: Graduation and College Attendance Rates

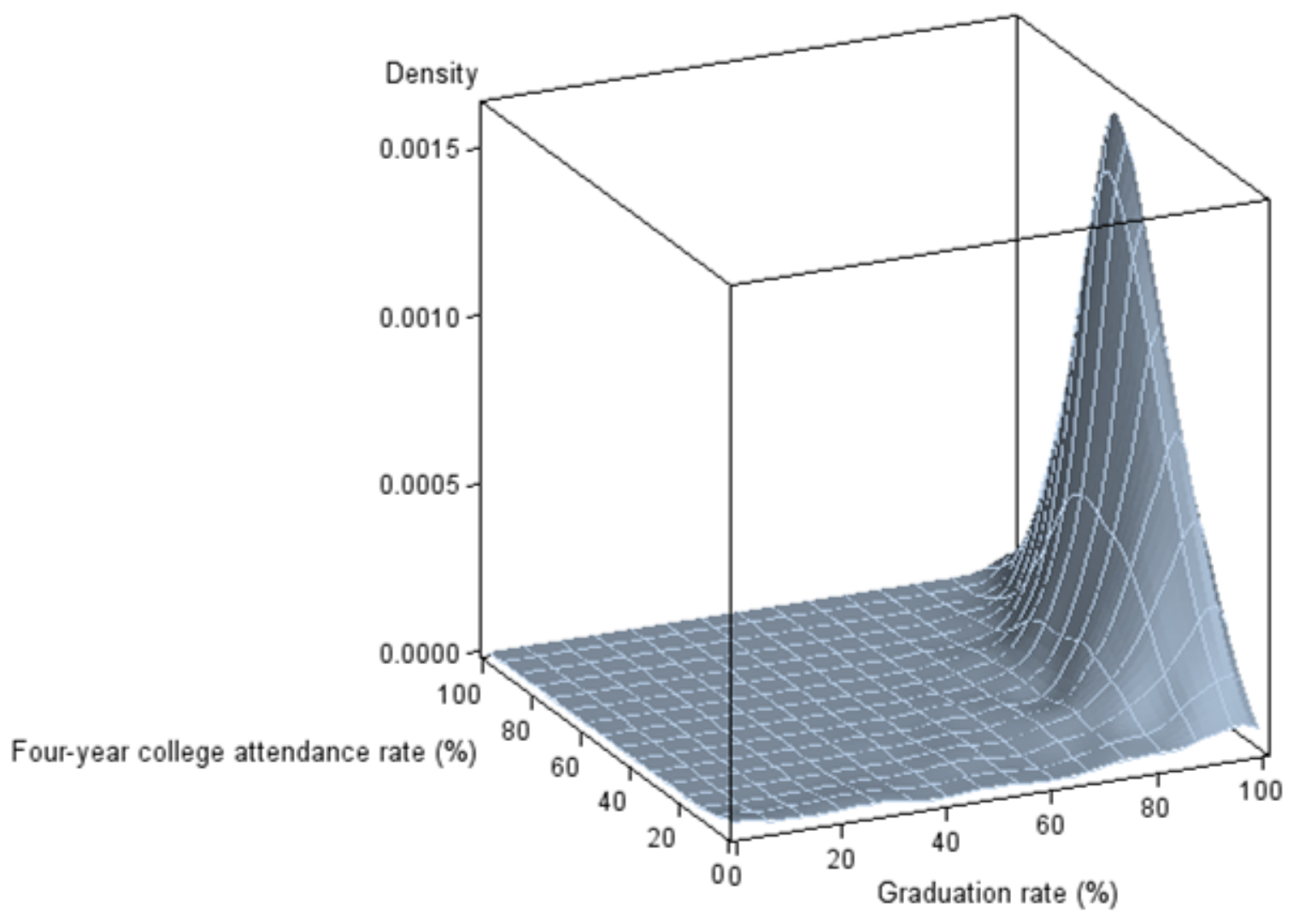


Figure 2: Quantile Regression Results for Four-year College Enrollment Model
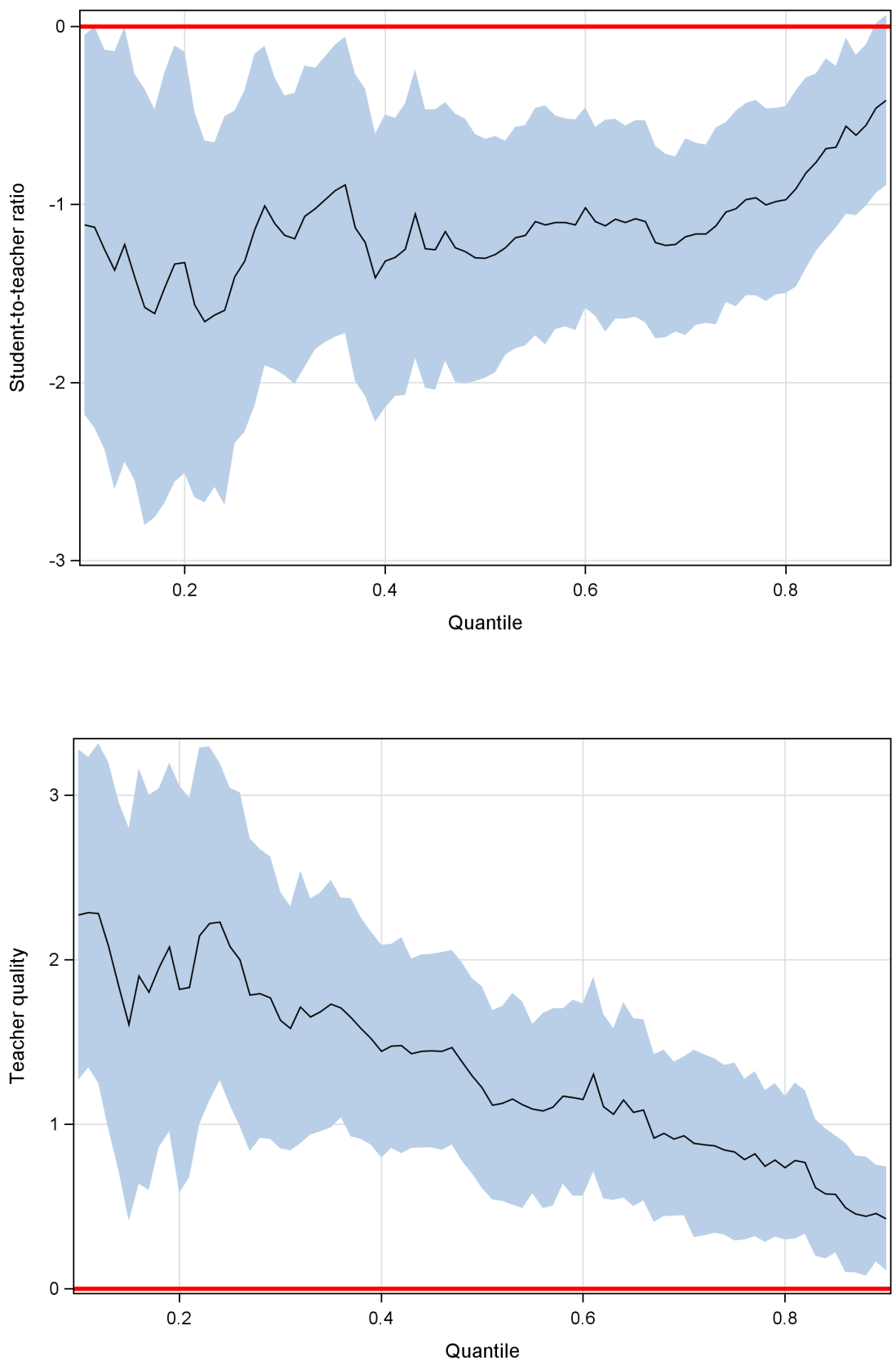

Note: Quantile regression estimate, $90 \%$ confidence band, and zero reference line are shown. In sample quantiles where the confidence band includes the zero line, changes in teacher inputs do not have a statistically significant marginal effect on student attainment measures. 
Figure 3: Quantile Regression Results for Graduation Rate Model
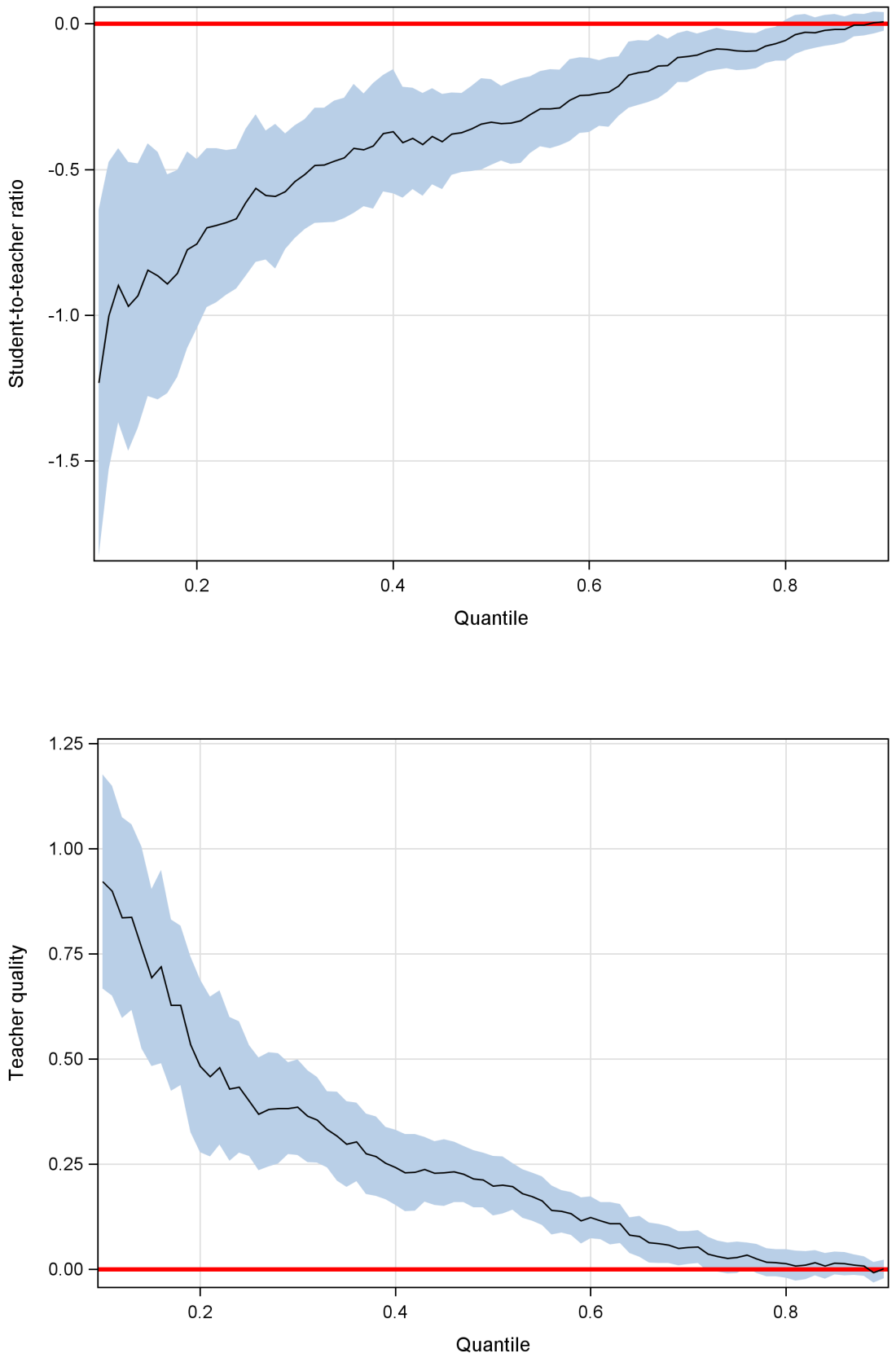

Note: Quantile regression estimate, $90 \%$ confidence band, and zero reference line are shown. In sample quantiles where the confidence band includes the zero line, changes in teacher inputs do not have a statistically significant marginal effect on student attainment measures. 